\title{
Recycling Technology of Bamboo Using Potassium Hydroxide
}

\author{
K. Nakaaze and T. Wajima
}

\begin{abstract}
The bamboo industry in Japan is declined, and disordered bamboo forests are increasing. Although maintenance of bamboo forest is needed, a large amount of bamboo wastes after logging is generated and left untreated. Therefore, new utilization of bamboo wastes after logging are desired. In this research, we aimed to develop a new recycling technology for bamboo using potassium hydroxide. By pyrolyzing bamboo using potassium hydroxide under an inert atmosphere, thermal decomposition of organic contents and alkali fusion of silica component inside the bamboo were carried out simultaneously to recover combustible gas, charcoal and silica component. The thermal decomposition behavior of bamboo, the properties of the obtained charcoal and extraction of silica in the presence of potassium hydroxide were investigated, and the optimum condition of bamboo recycling treatment was examined. As a result, it was found that when $1 \mathrm{~g}$ of bamboo was pyrolyzed at higher than $500{ }^{\circ} \mathrm{C}$ with $3 \mathrm{~g}$ of $\mathrm{KOH}$, the almost silica was extracted, a large amount of fuel gas generated, and a carbonized material with specific surface area of about $1000 \mathrm{~m}^{2} / \mathrm{g}$ was obtained.
\end{abstract}

Index Terms-Bamboo, potassium hydroxide, alkali fusion, pyrolysis, silica.

\section{INTRODUCTION}

The bamboo industry has declined due to the decrease in demand and an increase in the imported products. Approximately $350,000 \mathrm{~h} \alpha$ is disordered in approximately $400,000 \mathrm{~h} \alpha$ of the whole bamboo forest area in Japan. Bamboo growth is much faster than other trees, and it cause destruction of existing forests, induction of sediment collapse, damage of houses, etc. On the other hand, bamboo can be used as an effective natural resource by controlling the growth.

Bamboo is a Gramineae plant that absorbs a lot of silica $\left(\mathrm{SiO}_{2}\right)$ from the ground when growing. When bamboo is used as a biomass fuel, cracking by silica causes the problems for furnaces, chimney and so on. Silica is widely used for many industries and is important resources for Japan. In previous studies, silica is extracted from rice husk ash using alkali fusion method [1]. In addition, it is possible to recover charcoal, fuel gases by pyrolysis of bamboo, and the addition of hydroxide promotes thermal decomposition of bamboo to produce the charcoal with high surface area and the high amount of gases [2].

In this research, we aimed to develop a new recycling technology for bamboo using potassium hydroxide $(\mathrm{KOH})$.

Manuscript received September 4, 2019; revised December 7, 2019.

The authors are with the Department of Urban Environment Systems, Graduate School of Engineering, Chiba University, Japan (e-mail: nakaaze.koujirou@gmail.com, wajima@tu.chiba-u.jp).
Bamboo was heated in an inert atmosphere together with potassium hydroxide, and thermal decomposition treatment of bamboo body and alkali fusion treatment of silica component inside the bamboo was carried out simultaneously to recover combustible gas, charcoal and silica component. The thermal decomposition behavior of bamboo, the properties of the carbonized residue and the extraction of silica in the presence of potassium hydroxide was investigated, and the optimum condition of bamboo recycling treatment was examined.

\section{EXPERIMENT}

Bamboo powder, which was collected from Chiba prefecture, Japan, was pulverized to powder with diameter of less than $3 \mathrm{~mm}$ and air-dried to be used in this study. Table I shows the bamboo powder composition. The moisture content was measured using a moisture meter. In addition, the bamboo powder was burned at $700{ }^{\circ} \mathrm{C}$ in the air atmosphere, and the residual amount was defined as the ash content. Fixed carbon and Volatile matter amount were entrusted to Center for Analytical Instrumentation of Chiba University for measurement. The silica content in the bamboo sample was measured as described in the previous paper [2].

\begin{tabular}{|l|c|c|c|c|c|}
\hline \multirow{2}{*}{ Moisture } & \multirow{2}{*}{ Ash } & \multicolumn{3}{|c|}{$\begin{array}{c}\text { Fixed carbon and } \\
\text { Volatile matter }\end{array}$} & \multirow{2}{*}{$\mathrm{Si}$} \\
\cline { 3 - 5 } & & $\mathrm{C}$ & $\mathrm{H}$ & $\mathrm{N}$ & \\
\cline { 3 - 6 } & & & $5.4 \%$ & $0.2 \%$ & $2 \mathrm{mg} / \mathrm{g}$ \\
\hline
\end{tabular}

Experimental procedure for pyrolysis with $\mathrm{KOH}$ was shown in Fig. 1. Bamboo powder (1 g) was placed in a cylindrical stainless (SUS316) reactor together with $\mathrm{KOH}$ (1 - $3 \mathrm{~g}$ ) and heated to $300-600{ }^{\circ} \mathrm{C}$ in an electric tube furnace under a nitrogen atmosphere for $0-2 \mathrm{~h}$.

During heating, nitrogen gas was kept flowing at a flow rate of $50 \mathrm{~mL} / \mathrm{min}$. After heating, the reactor was cooled to room temperature while flowing nitrogen at the same flow rate, then nitrogen gas flow stopped, distilled water was added into the reactor, stirred with magnetic stirrer and filtered to recover an insoluble solid and a solution with soluble components in water. The concentration of silicon in the filtrate was measured with an atomic absorption spectrophotometer (PerkinElmer, AAnalyst 200), and the extracted amount of silica component was calculated. In addition, the gas generated during thermal decomposition was collected in a gas pack, and the amount of generated gas was measured using gas chromatograph (GC-8A, 
SHIMAZU). The solid residue was dried, and the weight of the residue was measured. The surface shape of the residue was observed with a scanning electron microscope (SEM) (JEOL, JSM-6510A) and specific surface areas of the residue were measured by a BET specific surface area measuring equipment (MacsorbModel-12, manufactured by MOUNTECH).
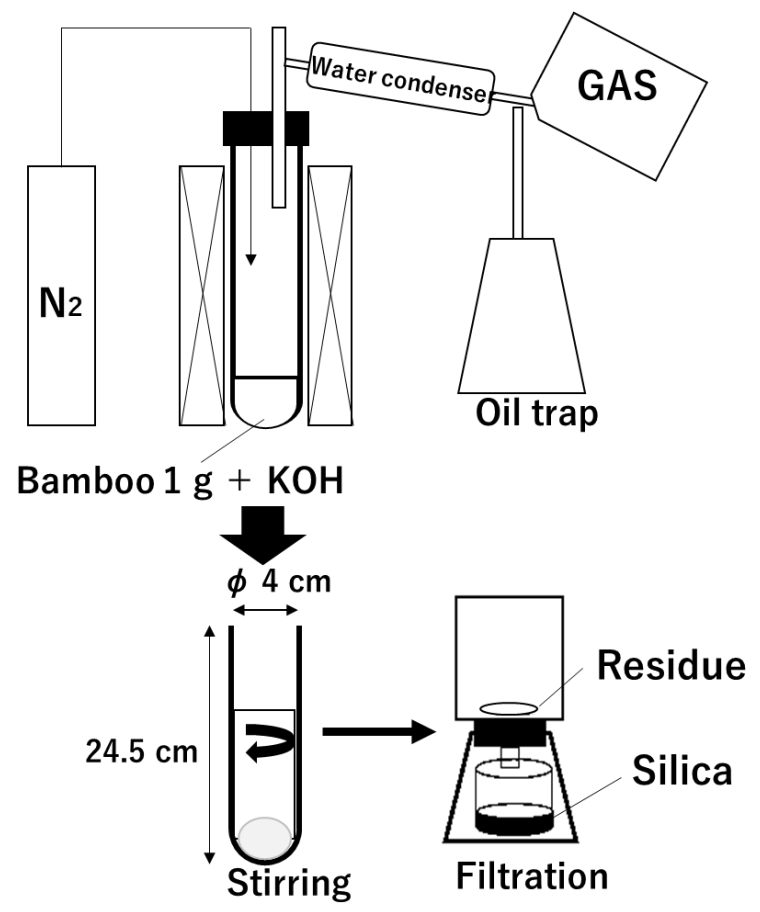

Fig. 1. Schematic diagram of an experiment and the reactor dimensions.

\section{RESUlTS AND DisCUSSION}

Residual weights under each condition are shown in Fig. 2. The heating time is $1 \mathrm{~h}$. As the temperature rises, the residual weight decreases (Fig. 1). When the thermal decomposition temperature is $300{ }^{\circ} \mathrm{C}$, the residual weight is $0.15 \mathrm{~g}$, and the residual weight decreases to $0.05 \mathrm{~g}$ with increasing heating temperature to $600{ }^{\circ} \mathrm{C}$. At $500{ }^{\circ} \mathrm{C}$, when potassium hydroxide addition is $1 \mathrm{~g}$, the residual weight is $0.12 \mathrm{~g}$, and the residual weight decreases slightly to $0.07 \mathrm{~g}$ with increasing potassium hydroxide addition $(3 \mathrm{~g})$. This suggests that an increase in the thermal decomposition temperature and amount of hydroxide addition promotes thermal decomposition of bamboo to reduce the weight of the residues.

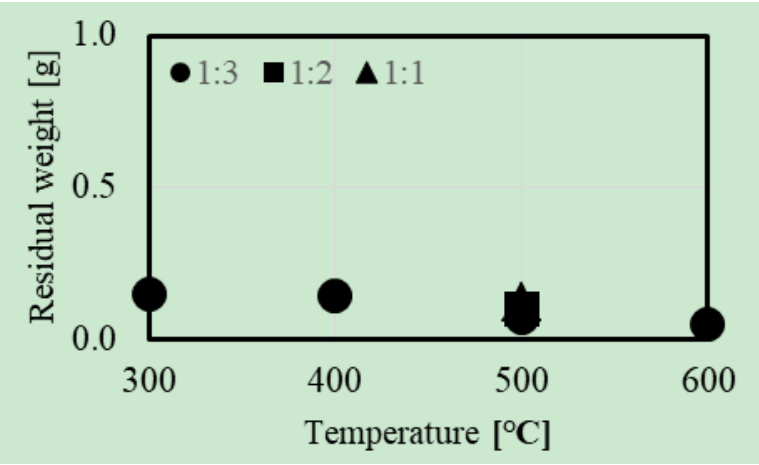

Fig. 2. Residual weights after pyrolysis.

Fig. 3 shows the specific surface area of the residue obtained under each condition. The heating time is $1 \mathrm{~h}$. The specific surface areas of the residue increase with increasing temperature and potassium hydroxide addition, and the residue with about $850 \mathrm{~m}^{2} / \mathrm{g}$ of specific surface area can be obtained when potassium hydroxide addition was $3 \mathrm{~g}$ at $500{ }^{\circ} \mathrm{C}$ and $600{ }^{\circ} \mathrm{C}$.

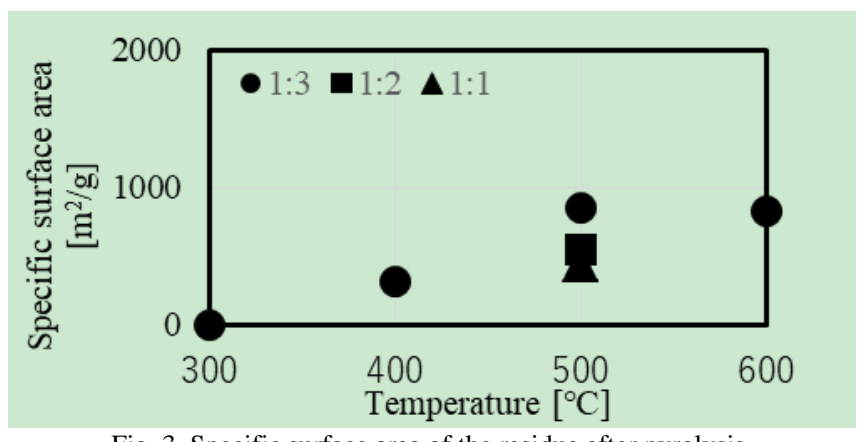

Fig. 3. Specific surface area of the residue after pyrolysis.

Fig. 4 shows SEM photographs of the residue after pyrolysis with $\mathrm{KOH}$ at $500{ }^{\circ} \mathrm{C}$. The heating time is $1 \mathrm{~h}$. The structure of tubular tissue, which is originated from raw bamboo, is observed in the residue without $\mathrm{KOH}$ at $500{ }^{\circ} \mathrm{C}$ (Fig. 4 (a)), while the structure of residue with $\mathrm{KOH}$ addition at $500{ }^{\circ} \mathrm{C}$ is different. With increasing $\mathrm{KOH}$ addition, the tubular structure is disappeared, flat surface with pore is observed in the residue with $1 \mathrm{~g}$ of $\mathrm{KOH}$ (Fig. 4(b)), and rough surface with pore is observed in the residue with $2 \mathrm{~g}$ and $3 \mathrm{~g}$ of $\mathrm{KOH}$ (Fig. 4 (c), (d)) to cause high specific surface area.
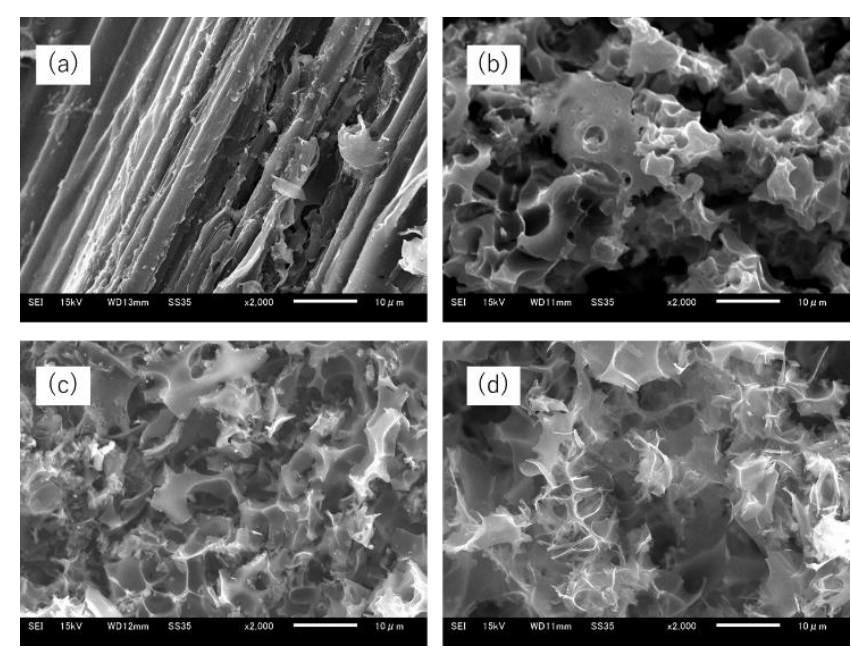

Fig. 4 SEM photographs of the residue after pyrolysis at $500^{\circ} \mathrm{C}$, (a) without $\mathrm{KOH}$, (b) with $1 \mathrm{~g}$ of $\mathrm{KOH}$ addition, (c) with $2 \mathrm{~g}$ of $\mathrm{KOH}$ addition, (b) with 3 $\mathrm{g}$ of $\mathrm{KOH}$ addition.

The extracted amount of silicon under each condition are shown in Fig. 5. The heating time is $1 \mathrm{~h}$. The silicon extraction amount is 0.6 to $1.8 \mathrm{mg} / \mathrm{g}$, which is almost same as the silicon content of bamboo $(1.1 \mathrm{mg} / \mathrm{g})$ [3]. This suggests that regardless of the thermal decomposition temperature, almost silica content in bamboo can be extracted by pyrolysis with $\mathrm{KOH}$.

Generated gas amounts under each condition are shown in Fig. 6. The heating time is $1 \mathrm{~h}$. As the temperature rises and the amount of hydroxide addition increases, the amount of generated gas increased. When potassium hydroxide addition is $3 \mathrm{~g}$, the gas amount is about $1.0 \mathrm{~L}$ at $500{ }^{\circ} \mathrm{C}$ and $600{ }^{\circ} \mathrm{C}$. These results indicate that hydroxide can promote the 
gasification of bamboo and the promotion is more effective at higher temperature of $500{ }^{\circ} \mathrm{C}$.

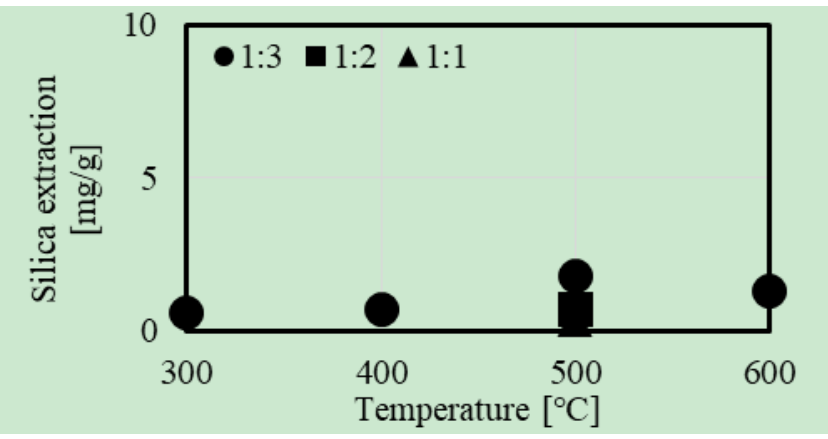

Fig. 5. Extracted amount of silicon under each condition.

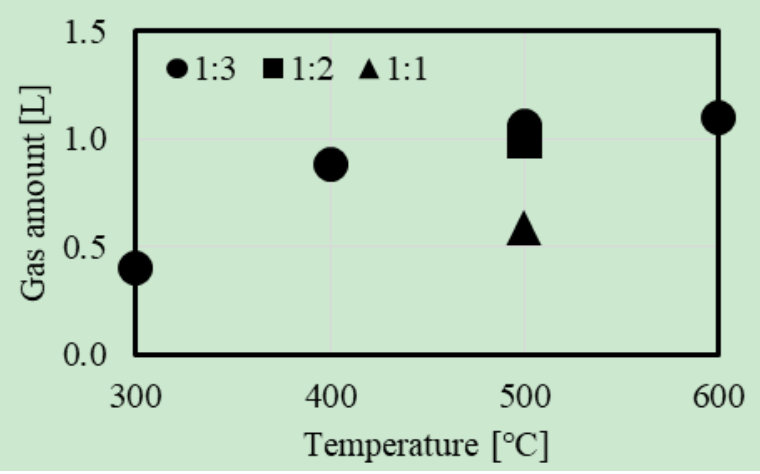

Fig. 6. Gas amounts generated during the pyrolysis.

Generated gas component under each condition are shown in Fig. 7. When potassium hydroxide addition was lower than $2 \mathrm{~g}$, incombustible gas $\left(\mathrm{CO}\right.$ and $\left.\mathrm{CO}_{2}\right)$ are detected $(15 \sim 27 \%$ in the generated gas). On the other hand, when potassium hydroxide addition is $3 \mathrm{~g}$, these gases are lower than $4 \%$ and combustible gas $\left(\mathrm{H}_{2}\right.$ and $\left.\mathrm{CH}_{4}\right)$ are over $96 \%$. This suggests that an increase in the addition of potassium hydroxide improves the purity of fuel gases.

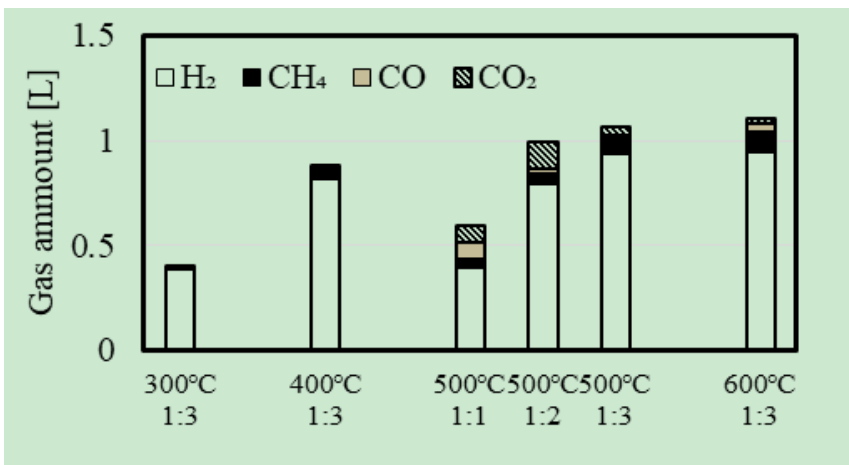

Fig. 7. Gas component generated during the pyrolysis.

From these results, it is suggested that the optimum condition of bamboo recycling treatment is more than $500{ }^{\circ} \mathrm{C}$ of heating temperature and $3 \mathrm{~g}$ of $\mathrm{KOH}$ addition.

The influence of the thermal decomposition time were investigated. Heating temperature and the potassium hydroxide addition was fixed at $500{ }^{\circ} \mathrm{C}$ and $3 \mathrm{~g}$, respectively. Also, in order to investigate the effect of kind of hydroxide, the experiment using $\mathrm{NaOH}$ was compared with that using $\mathrm{KOH}$ under the same condition.

Residual weights during the pyrolysis are shown in Fig. 8.

Regardless of thermal decompotision time and kind of hydroxide, the weights are almost same $(0.07 \sim 0.11 \mathrm{~g})$. This suggests that thermal decomposition of bamboo occurs rapidly regardless of kind of hydroxide under this experimental condition.

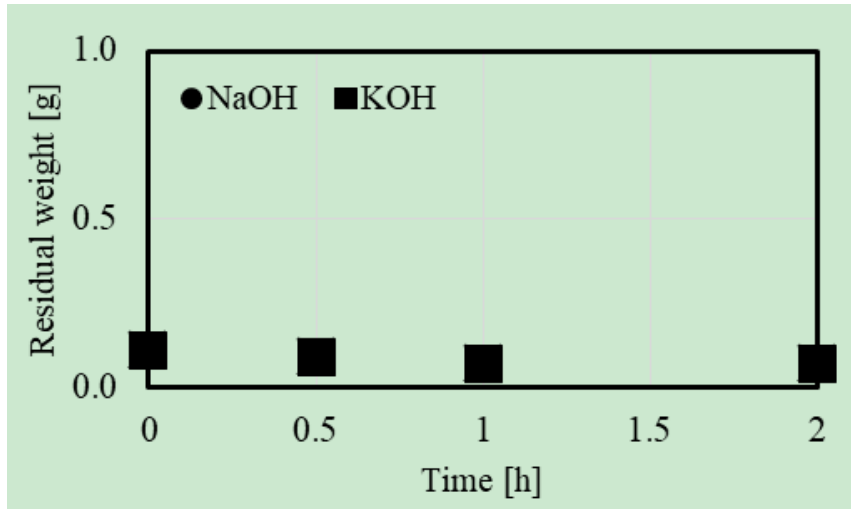

Fig. 8. Residual weights after pyrolysis with $\mathrm{KOH}$ and $\mathrm{NaOH}$.

Fig. 9 shows the specific surface area of the residue during pyrolysis. When potassium hydroxide is added, the specific surface areas of the residue are about $1000 \mathrm{~m}^{2} / \mathrm{g}$ regardless of the thermal decomposition time. In the other hand, when sodium hydroxide is added, the specific surface areas are 1100 to $1500 \mathrm{~m}^{2} / \mathrm{g}$.

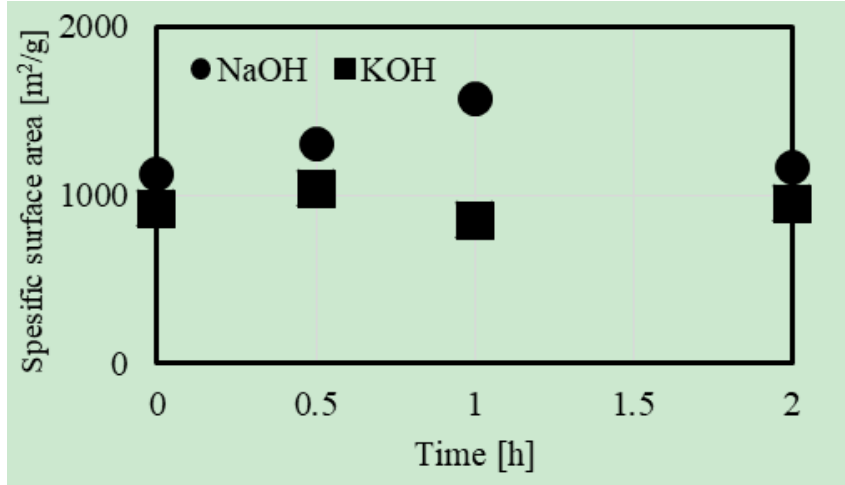

Fig. 9. Specific surface area of the residue after pyrolysis with $\mathrm{KOH}$ and $\mathrm{NaOH}$.

Fig. 10 shows SEM photographs of the residue obtained using $\mathrm{NaOH}$ and $\mathrm{KOH}$. Flat planes and several pores can be confirmed in the residue with $\mathrm{NaOH}$ addition (Fig. 10(a)), while these structures are not observed on the surface of the residue with $\mathrm{KOH}$ (Fig. 10 (b)). It is reported that the intercalation of alkali metal between the graphitic type layers is one of the steps in the chemical activation of carbon, and $\mathrm{K}$ can be inserted into highly crystalline materials such as graphite-like structures, while $\mathrm{Na}$ can only be inserted into poorly crystalline materials [4]-[6]. Furthermore, it is also reported that activated carbon is composed of three parts, such as graphite-like microcrystalline, single reticular-plane carbon and non-organized carbon [7]. Therefore, it is considered that $\mathrm{Na}$ react with only non-organized carbon and pores generated, and the other part of bamboo body remained as flat planes, while $\mathrm{K}$ react with all surface of bamboo and rough surface with pore is formed. The difference of the structure causes the difference of specific surface area.

The extracted amount of silica using $\mathrm{KOH}$ and $\mathrm{NaOH}$ are shown in Fig. 11. Regardless of kind of hydroxide and thermal decomposition time, silica extraction amounts are 1.0 to $1.8 \mathrm{~g}$. This suggests that almost silica content in bamboo is 
extracted rapidly regardless of kind of hydroxide.

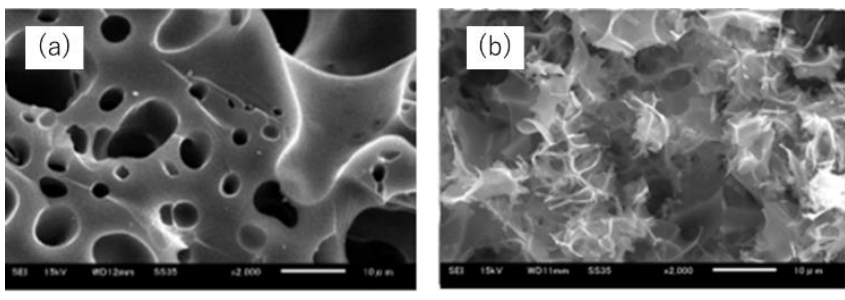

Fig. 10. SEM photographs of the residue after pyrolysis at $500{ }^{\circ} \mathrm{C}$, (a) with 3 $\mathrm{g}$ of $\mathrm{NaOH}$ addition and (b) with $3 \mathrm{~g}$ of $\mathrm{KOH}$ addition.

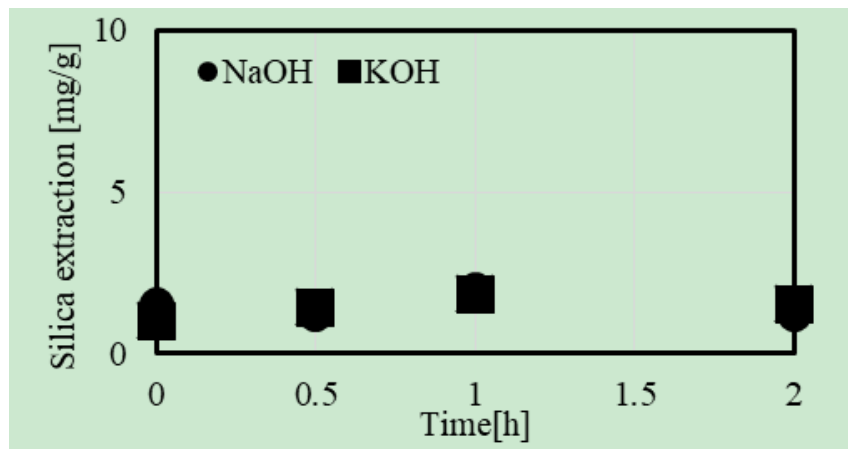

Fig. 11. Extracted amount of silicon under each condition with $\mathrm{KOH}$ and $\mathrm{NaOH}$.

Generated gas amounts during pyrolysis are shown in Fig. 12. The amount of generated gas increases and becomes constant after $0.5 \mathrm{~h}$ pyrolysis regardless of the kind of hydroxide. These results indicate that the thermal decomposition occurs within $0.5 \mathrm{~h}$.

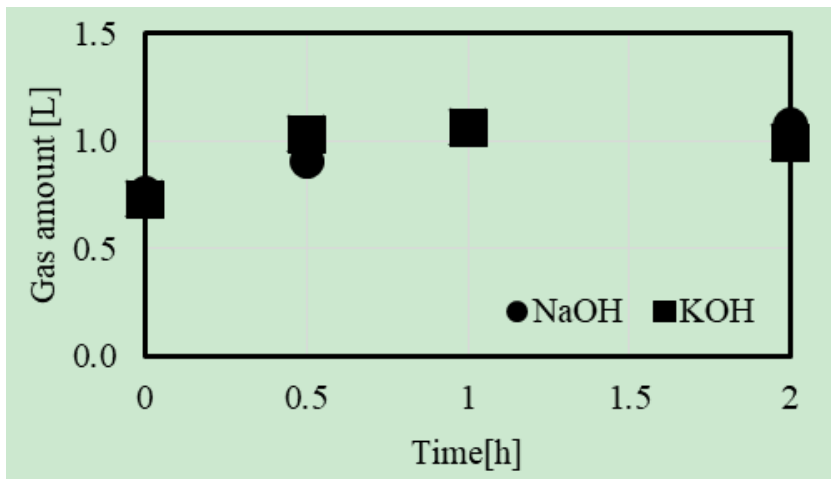

Fig. 12. Gas amounts generated during the pyrolysis with $\mathrm{KOH}$ and $\mathrm{NaOH}$.

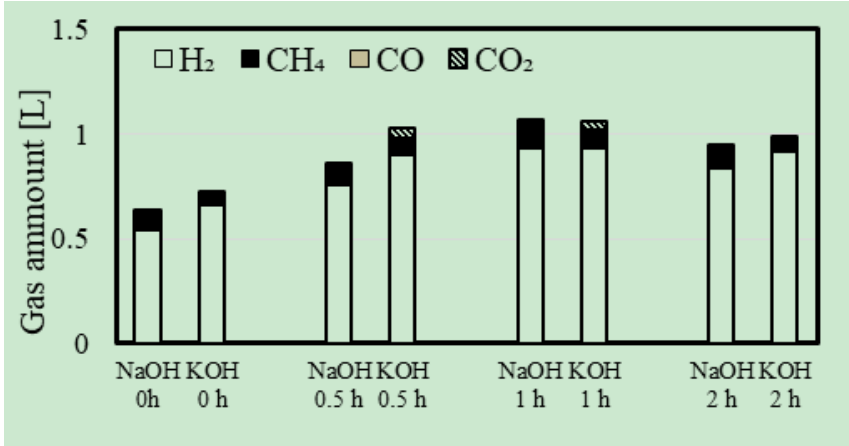

Fig. 13. Gas component generated during the pyrolysis with $\mathrm{KOH}$ and $\mathrm{NaOH}$.

Generated gas component using $\mathrm{KOH}$ and $\mathrm{NaOH}$ are shown in Fig. 13. Regardless of kind of hydroxide and thermal decomposition time, the percent of $\mathrm{H}_{2}$ in the generated gas is about 85 to $90 \%, \mathrm{CH}_{4}$ accounted for about 5 to $10 \%$, and the amounts of $\mathrm{CO}$ and $\mathrm{CO}_{2}$ are minor $(<4 \%)$, which means that fuel gas can be recovered within $0.5 \mathrm{~h}$ by pyrolysis with hydroxide.

\section{CONCLUSION}

We aimed to develop a new recycling technology for bamboo using potassium hydroxide. By pyrolyzing bamboo using potassium hydroxide under an inert atmosphere, thermal decomposition of organic contents and alkali fusion of silica component inside the bamboo were carried out simultaneously to recover combustible gas, charcoal and silica component.

As a result, it was found that when $1 \mathrm{~g}$ of bamboo was pyrolyzed at higher than $500{ }^{\circ} \mathrm{C}$ with $3 \mathrm{~g}$ of $\mathrm{KOH}$, the almost silica was extracted, a large amount of gas generated, and a carbonized material with specific surface area of about 1000 $\mathrm{m}^{2} / \mathrm{g}$ was obtained. It is considered that thermal decomposition occurred completely within 0.5 hour under this condition. Comparing the results of $\mathrm{KOH}$ and $\mathrm{NaOH}$, residual weights, gas amount and silica extraction amount were same results, while $\mathrm{NaOH}$ was superior to $\mathrm{KOH}$ for specific surface area of the obtained residue due to the different structure.

\section{CONFLICT OF INTEREST}

The authors declare no conflict of interest.

\section{AUTHOR CONTRIBUTIONS}

K. Nakaaaze conducted the research, analyzed the data and wrote the paper, T.Wajima revised the manuscript, and all authors had approved the final version.

\section{ACKNOWLEDGMENT}

This work was supported by Takahashi Industrial and Economic Research Foundation.

\section{REFERENCES}

[1] R. Yuvakkumar, V. Elango, V. Rajendran, and N. Kannan "High-purity nano silica powder from rice husk using a simple chemical method," Experimental Nanoscience, vol. 9, pp. 272-281, 2014.

[2] K. Nakaaze and T. Wajima, "A novel recycling technology of bamboo using NaOH," Journal of Engineering and Science Research, vol. 2, pp. 7-12, 2018

[3] Z. Yuan, Y. Wen, N. S. Kapu, R. Beatson, and D. M. Martinez, “A biorefinery scheme to fractionate bamboo into high-grade dissolving pulp and ethanol," Biotechnology for Biofuels, vol. 10, no. 38, 2017.

[4] L. Muniandy, F. Adam, A. R. Mohamed, and E. P. Ng, "The synthesis and characterization of high purity mixed microporous/mesoporous activated carbon from rice husk using chemical activation with $\mathrm{NaOH}$ and KOH," Microporous and Mesoporous Materials, vol. 197, pp. 316-323, 2014.

[5] M. A. Lillo-Rodenas, D. Cazorla-Amoros, and A. Linares-Solano, "Understanding chemical reactions between carbons and $\mathrm{NaOH}$ and $\mathrm{KOH}$, An insight into the chemical activation mechanism," CARBON, vol. 41, pp. 267-275, 2003

[6] O. Boujibarab, F. Ghamouss, A. Ghosh, O. Achak, T. Chafik, "Activated carbon with exceptionally high surface area and tailored nanoporosity obtained from natural anthracite and its use in supercapacitors," Journal of Power Sources, vol. 436, no. 226882 2019.

[7] G. Selvaraju and N. A. B. Bakar, "Production of a new industrially viable green-activated carbon from Artocarpus integer fruit processing waste and evaluation of its chemical, morphological and adsorption 
properties," Journal of Cleaner Production, vol. 141, pp. 989-999, 2017.

Copyright $\odot 2020$ by the authors. This is an open access article distributed under the Creative Commons Attribution License which permits unrestricted use, distribution, and reproduction in any medium, provided the original work is properly cited (CC BY 4.0).

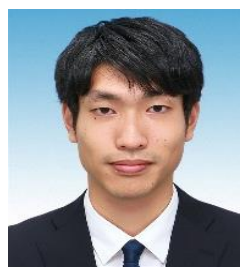

Kojiro Nakaaze was born in August 1995 in Tokyo Prefecture. He attends in the master's course of the Department of Urban Environment Systems, Graduate School of Engineering, Chiba University, Japan.

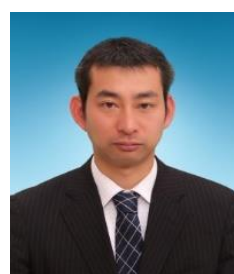

Takaaki Wajima was born in February 1976 in Saga Prefecture. He has been an associate professor in the Department of Urban Environment Systems, Graduate School of Engineering, Chiba University, Japan, since 2013. He received his bachelor's degree and master's degree in resource engineering from Kyoto University, japan, in 1998 and 2000, respectively, and his Ph.D in environmental mineralogy and technology from Kyoto University, Japan, in2004. In 2004 he moved to the Institute of Ocean Energy at Saga University to work as a postdoctoral researcher, and 2007 to 2013 he was an Assistant professor at Akita University, Japan. His main research interests are waste recycling, resource recovery, and environmental purification. 